\title{
Efeito do escore de condição corporal na dinâmica folicular final e fertilidade de éguas da raça Mangalarga Marchador
}

Miguel Pizzolante Bottino;, Augusto Siqueira Lemos, Bruna Oliveira Dias, Sarah Maria Godtfredsen, José Nélio Sousa Sales, Flamarion Tenório de Albuquerque

Universidade Federal de Lavras (UFLA), Lavras, MG, Brasil

*Autor correspondente

e-mail: miguelbottino@yahoo.com.br

\section{Resumo}

O manejo nutricional inadequado e a redução da gordura corporal estão associados à diminuição na eficiência reprodutiva. A leptina é um hormônio derivado dos adipócitos, capaz de atuar como um sinalizador do status nutricional ao hipotálamo. Concentrações de leptina geralmente variam diretamente com a porcentagem de gordura corporal. Em roedores, baixas concentrações de leptina promovem redução na liberação das gonadotrofinas, podendo reduzir a atividade ovariana ou até mesmo promover anestro. Uma alternativa eficiente para se quantificar a reserva de gordura corporal é a avaliação do escore de condição corporal (ECC). Assim, o objetivo do presente estudo foi avaliar o efeito do escore de condição corporal na dinâmica folicular final e na fertilidade de éguas adultas da raça Mangalarga Marchador. No estudo foram utilizadas 189 éguas (95 paridas e 94 não paridas) com ECC variando de 3 a 8 (escala de 1 a 9). Na avaliação do estudo, as éguas foram divididas em dois grupos de acordo com o escore de condição corporal (Grupo Alto ECC - ECC $\geq 7$ e Grupo Baixo ECC - ECC < 7). Durante o estudo, após exame ultrassonográfico, os animais que apresentaram corpo lúteo receberam 6,71 mg de dinoprost trometamina (Lutalyse ${ }^{\circledR}$, Pfizer, Brasil), IM. A partir do momento em que o folículo dominante atingiu o diâmetro entre 33 a $35 \mathrm{~mm}$, os animais passaram a ser examinados diariamente, a fim de mensurar o diâmetro do folículo dominante e grau de edema uterino (escala de 0 a 3). As éguas com folículo dominante com diâmetro igual ou superior a 37 mm receberam 1000 UI de hCG (Chorulon ${ }^{\circledR}$, MSD, Holanda), IV, para induzir a ovulação. A determinação da ovulação foi feita por identificação ultrassonográfica de estrutura luteinizada no local do folículo dominante previamente visualizado. 0 diagnóstico de gestação foi realizado 12 a 14 dias após a ovulação por exame ultrassonográfico. Os dados foram analisados pelo procedimento GLIMMIX do SAS. O ECC médio do Grupo Alto ECC foi de 7,17 e do Grupo Baixo ECC foi de 5,27. Não foi verificada diferença entre os grupos de escore corporal em relação ao diâmetro inicial do folículo dominante [Grupo Alto ECC (35,68 \pm 0,57mm) e Grupo 
Baixo ECC $(35,67 \pm 0,37 \mathrm{~mm}) ; \mathrm{P}=0,73]$, diâmetro do folículo ovulatório [Grupo Alto ECC $(43,91 \pm 0,57 \mathrm{~mm}$ ) e Grupo Baixo ECC $(43,33 \pm 0,55 \mathrm{~mm}) ; \mathrm{P}=0,52$ ], crescimento folicular [Grupo Alto ECC $(2,92 \pm 0,16 \mathrm{~mm}$ ) e Grupo Baixo ECC $(2,64 \pm 0,18 \mathrm{~mm}) ; \mathrm{P}=0,22]$, diâmetro folicular no momento da administração de hCG [Grupo Alto ECC (40,93 \pm 0,40mm) e Grupo Baixo ECC $(40,80 \pm 0,38 \mathrm{~mm}) ; \mathrm{P}=0,84$ ], diâmetro folicular no momento da administração de prostaglandina [Grupo Alto ECC $(26,28 \pm 1,14 \mathrm{~mm})$ e Grupo Baixo ECC $(27,58$ $\pm 1,26 \mathrm{~mm}) ; \mathrm{P}=0,52$ ], edema uterino na indução da ovulação [Grupo Alto ECC $(2,15 \pm 0,08 \mathrm{~mm})$ e Grupo Baixo ECC (1,98 $\pm 0,09 \mathrm{~mm}) ; \mathrm{P}=0,12$ ], edema uterino após ovulação [Grupo Alto ECC $(0,42 \pm 0,07 \mathrm{~mm}) \mathrm{e}$ Grupo Baixo ECC $(0,26 \pm 0,06 \mathrm{~mm}) ; \mathrm{P}=0,07$ ] e taxa de prenhez [Grupo Alto ECC 57,5\% (50/87) e Grupo Baixo ECC 44,4\% (28/63); P = 0,12]. No entanto, éguas do Grupo Alto ECC apresentaram maior diâmetro máximo do folículo dominante quando comparadas as do Grupo de Baixo ECC [Grupo Alto ECC (44,42 \pm 0,53mm); Grupo Baixo ECC (43,07 $\pm 0,41 \mathrm{~mm}) ; \mathrm{P}=0,05]$. Apesar de não ser estatístico, a diferença de $13,1 \%$ nos resultados da taxa de prenhez entre os grupos estudados chama atenção e sugere a necessidade de mais estudos. Dessa forma, conclui-se que o ECC interfere no diâmetro máximo do folículo dominante de éguas da raça Mangalarga Marchador.

Palavras-chave: ECC. Prenhez. Crescimento folicular. 